\title{
Integrating remote sensing-derived evapotranspiration and ground-monitored discharge data for the improvement of hydrological modelling: A case study of the Sekong River Basin
}

\author{
Raksmey Ang ${ }^{1}$, S. Shrestha ${ }^{1}$, Salvatore Virdis ${ }^{1}$, and Saurav $\mathrm{KC}^{1}$ \\ ${ }^{1}$ Asian Inst Technol
}

February 10, 2021

\begin{abstract}
This study analyses the efficiency of integrating remotely sensed evapotranspiration into the process of hydrological model calibration. A joint calibration approach, employing both remote sensing-derived evapotranspiration and ground-monitored streamflow data was compared with a conventional ground-monitored streamflow calibration approach through physicallybased hydrological, Soil and Water Assessment Tool (SWAT) model setups. The efficacy of the two calibration schemes was investigated in two modelling setups: 1) a physically-based model with only the outlet gauge available for calibration, and 2) a physically-based model with multiple gauges available for calibration. Joint calibration was found to enhance the skill of hydrological models in streamflow simulation compared to ground-monitored streamflow-only calibration at the unsaturated zone in the upstream area, where essential information on evapotranspiration is also required. Additionally, the use of remote sensing-derived evapotranspiration can significantly improve high flow compared to low flow simulation. A more consistent model performance improvement, obtained from using remote sensing-derived evapotranspiration data was found at gauged sites not used in the calibration, due to additional information on spatial evapotranspiration in internal locations being enhanced into a process-based model. Eventually, satellite-based evapotranspiration with fine resolution was found to be competent for calibrating and validating the hydrological model for streamflow simulation in the absence of measured streamflow data for model calibration. Furthermore, the impact of using evapotranspiration for hydrologic model calibration tended to be stronger at the upstream and tributary sub-basins than at downstream sub-basins.
\end{abstract}

\section{Hosted file}

Manuscript.pdf available at https://authorea.com/users/394889/articles/508219-integratingremote-sensing-derived-evapotranspiration-and-ground-monitored-discharge-data-for-theimprovement-of-hydrological-modelling-a-case-study-of-the-sekong-river-basin 